\title{
Um olhar sobre as práticas docentes na avaliação de alunos com currículo específico individual
}

\section{António Guerreiro ${ }^{a}$, Maria Teresa Roque ${ }^{b}$}

${ }^{a}$ Universidade do Algarve, Faro, Portugal, aguerrei@ualg.pt, ${ }^{\mathrm{b}}$ Agrupamento de Escolas Manuel Teixeira Gomes, Portimão, Portugal, mtsroque@gmail.com.

\section{Resumo}

Uma incapacidade cognitiva, física, social ou emocional não pode constituir um impedimento à participação social e ao sucesso das crianças numa escola inclusiva e democrática. Este estudo centra-se na problemática da avaliação de alunos com necessidades educativas especiais do $2{ }^{\circ}$ ciclo no ensino básico, concretamente dos alunos com currículo específico individual. O estudo analisa as práticas de avaliação docente destes alunos, assumindo como objetivos: (i) a identificação das práticas de avaliação dos alunos com currículo específico individual; (ii) a compreensão sobre o modo como o currículo específico individual é influenciado pelo desempenho dos alunos; (iii) o conhecimento das perspetivas dos professores face à avaliação destes alunos, bem como à inclusão dos mesmos na turma e na escola.

O estudo adotou uma metodologia qualitativa centrada no paradigma interpretativo, realizando um estudo de caso de dois alunos, João e Pedro (nomes fictícios), com currículo específico individual, incluídos numa mesma turma do 5. ${ }^{\circ}$ ano, integrando, no estudo, seis professores do $2 .^{\circ}$ ciclo do ensino básico, do conselho de turma, de um Agrupamento de Escolas do distrito de Faro, Portugal. Os instrumentos de recolha de dados constituíram-se por entrevistas semiestruturadas, conversas informais e análise documental. Os dados recolhidos foram objeto de análise de conteúdo tendo por referência um sistema de categorias surgidos das opiniões dos professores entrevistados.

As conclusões apontam para a necessidade de realçar o contributo que a avaliação tem para o sucesso dos alunos, para a reestruturação do currículo específico individual e para o papel dos professores no desenvolvimento de práticas de avaliação formativas. Estas contribuem para as aprendizagens dos alunos com necessidades educativas especiais, em que as relações interpessoais, o reforço positivo e a autoestima são primordiais. 
Palavras-chave: Avaliação, Necessidades Educativa Especiais, Currículo Específico Individual, Escola Inclusiva.

\section{Introdução}

A Educação deve ser encarada como um fator facilitador do desenvolvimento e da funcionalidade de todos os seres humanos. Este estudo tem como objetivo fundamental refletir sobre o processo de avaliação dos alunos com currículo específico individual, na realidade portuguesa, no que concerne a uma escola pública do $2 .^{\circ}$ ciclo do ensino básico.

\section{Educação Inclusiva}

A educação inclusiva deve alterar o sistema educativo para que este se ajuste ao aluno e não o contrário, criando assim, um ambiente onde a paz, a tolerância, a justiça social, as necessidades básicas e os direitos sejam uma realidade para todos. Esta premissa levanta questões muito concretas que Reis e Neves (2011) realçam ao salientarem que importa refletir sobre a prioridade da inclusão na educação e sobre o caráter universal da educação inclusiva. Não nos podemos esquecer que o benefício da inclusão não é só para crianças com deficiência, mas sim para toda a comunidade escolar, originando impactos, no sentido da cidadania, da diversidade e da aprendizagem.

A inclusão torna as escolas lugares acolhedores e estimulantes, tanto para os professores e os assistentes operacionais, como para os alunos. A inclusão em educação implica: (i) a valorização de todos por igual; (ii) a redução da exclusão de alunos e o aumento da sua participação; (iii) a resposta à diversidade dos alunos, reorganizando as políticas, culturas e práticas nas escolas; (iv) a redução das barreiras à aprendizagem e à participação de todos; (v) a utilização de estratégias adequadas para que todos possam beneficiar e utilizar as diferenças entre os alunos como recurso de apoio à aprendizagem (Booth \& Ainscow, 2002).

A flexibilidade e a diversidade participam de igual modo na definição de escola inclusiva, uma vez que a educação deve permitir às crianças e aos jovens atingirem o seu máximo potencial em termos das capacidades cognitivas, emocionais e criativas. Um olhar inclusivo sobre a qualidade da educação visa a necessidade de assegurar que as oportunidades de aprendizagens contribuam para uma inclusão na sociedade, deseja-se por isso a participação de todos (UNESCO, 2005). Esta qualidade nas aprendizagens pode ser melhorada pela 
flexibilidade curricular, através de mudanças de metodologias e na avaliação, uma vez que os alunos necessitam de seguir caminhos diferentes para todos atingirem o sucesso educativo.

\section{Avaliação dos Alunos com currículo específico individual}

A avaliação refere-se essencialmente à avaliação das aprendizagens, envolvendo “interpretação, reflexão, informação e decisão sobre os processos de ensino e aprendizagem, tendo como principal função ajudar a promover ou melhorar a formação dos alunos" (Abrantes, 2001, p.46-47). A avaliação é a "recolha sistemática de informação sobre a qual se possa formular um juízo de valor que facilite a tomada de decisões" (Peralta, 2002, p.24).

De salientar que a avaliação engloba a dimensão cognitiva, que integra conhecimentos e capacidades, e a dimensão atitudinal, integrando o comportamento, atitudes e responsabilidade. Colôa Dias (2014) refere a avaliação como sendo um instrumento indispensável à monitorização do progresso dos alunos e à qualidade educativa dos estabelecimentos de ensino. Menciona ainda que "o processo de avaliação pedagógica (...) [pode ser] encarado como processo de avaliação para as aprendizagens, mais do que como [o] processo de avaliação de aprendizagens" (p. iii).

O objetivo da avaliação é facilitar a intervenção mais adequada para potenciar as aprendizagens, redundando numa melhoria dos resultados de todos os alunos, através de uma eficaz utilização da informação recolhida dos diferentes instrumentos de avaliação. A avaliação inicia-se com o processo de avaliação de diagnóstico, progride com a avaliação contínua ou continuada e finaliza com a avaliação sumativa. No caso de alunos com currículo específico individual, após a recolha das informações resultantes da avaliação diagnóstica, será necessário efetuar um currículo específico para o aluno, onde constem os conteúdos a abordar, as estratégias a utilizar, as competências a adquirir, o local da realização das atividades propostas (funcionais ou não), os recursos a utilizar e os instrumentos de avaliação.

O professor de educação especial tem um papel essencial na dinamização da mudança que a escola inclusiva reclama, em consonância com os normativos legais em Portugal: "uma aposta decisiva na autonomia das escolas e dos seus profissionais, designadamente através do reforço da intervenção dos docentes de educação especial, enquanto parte ativa das equipas educativas na definição de estratégias e no acompanhamento da diversificação curricular" (Decreto-lei 54/2018). O professor de educação especial deve motivar os restantes professores a quererem saber sempre mais e a estarem abertos à inovação e à 
mudança, terem um conhecimento abrangente das crianças, das suas capacidades em cada fase do seu desenvolvimento, dos seus interesses, competências e necessidades, bem como da forma como estruturam o pensamento.

\section{Enquadramento Metodológico}

A questão de análise prende-se com a avaliação de alunos com currículo específico individual (Roque, 2018), mais concretamente com as práticas pedagógicas utilizadas na avaliação destes alunos. Tendo em conta os objetivos, optou-se por metodologias qualitativas e interpretativas para compreender a realidade tal como é vivida e percebida pelos sujeitos (Bogdan \& Biklen, 1994). Este estudo pretende responder à questão: Quais as práticas de avaliação dos alunos com currículo específico individual? E apresenta como objetivos: i) Identificar as práticas de avaliação dos alunos com currículo específico individual; ii) Compreender se este currículo específico é influenciado pelo desempenho dos alunos; iii) Conhecer as perspetivas dos professores face à avaliação destes alunos, bem como à inclusão dos mesmos na turma e na escola.

\subsection{Participantes}

Este estudo desenvolveu-se numa escola básica do $2 .^{\circ}$ e $3 .^{\circ}$ ciclos de um agrupamento de escolas do distrito de Faro, Portugal, com os professores (nomes fictícios) de Português e Cidadania e Desenvolvimento (Alice), Inglês (Isabel), História e Geografia de Portugal (Carolina), Ciências Naturais e Matemática (Ana), Educação Física (Luís), Educação Musical (Nuno) e Educação Visual e Tecnológica (segunda autora) e com dois alunos (João e Pedro, nomes fictícios) com currículo específico individual do $5 .^{\circ}$ ano de escolaridade. Aos participantes foi garantido o direito ao anonimato e à confidencialidade e assegurado que os dados não são utilizados por terceiros nem para outro fim que não seja este estudo.

A professora Alice tem 16 anos de serviço. Tem formação em dislexia. A professora Isabel tem 26 anos de serviço. A professora Carolina tem 25 anos de serviço. Não tem formação específica em educação especial, mas considera ter experiência com alunos com currículo específico individual. A professora Ana tem 22 anos de serviço. O professor Luís tem 8 anos de serviço. Tem formação específica em educação especial. O professor Nuno tem 6 anos de serviço. Estes professores assumem a sua experiência e o apoio dos docentes de educação especial como aspetos determinantes para o sucesso do seu trabalho com estes alunos. 
A turma estava constituída por 20 alunos, 11 rapazes e 9 raparigas, com idades compreendidas entre os 9 e os 12 anos. O João tinha 12 anos. Foi referenciado no $3 .^{\circ}$ ano por revelar dificuldades continuadas ao nível da aprendizagem. No início do $5 .^{\circ}$ ano, o João não conseguia ler, apresentava alguma autonomia, contava até 20 com ajuda e realizava operações de adição muito simples, desenhava bem para a sua faixa etária. O Pedro tinha 11 anos. Foi referenciado no $2 .^{\circ}$ ano por revelar dificuldades continuadas ao nível da aprendizagem. No início do $5 .^{\circ}$ ano, o Pedro conseguia ler, mas não compreendia o que lia, era pouco autónomo, contava até 20 e fazia operações simples de adição e subtração, não conseguia contar de 10 em 10 e desenhava ao nível do pré-escolar.

O João e o Pedro acompanhavam a turma em 23 tempos letivos, sendo 9 tempos em Educação Visual e Tecnológica, Educação Musical, Educação Física e Cidadania e Desenvolvimento e 14 tempos em Português, Inglês, História e Geografia de Portugal, Matemática e Ciências Naturais, 6 tempos em atividades com a professora de educação especial e 2 tempos numa atividade desportiva, o Boccia.

\subsection{Recolha e análise de dados}

Os instrumentos de recolha de informação adotados foram a entrevista semiestruturada aos docentes, a análise documental, concretamente o Projeto Educativo do Agrupamento de Escolas e os documentos dos processos dos alunos, incluindo o currículo específico individual, e os registos complementares, notas retiradas depois das entrevistas, em conversas informais e observação de aulas de Educação Visual e Tecnológica e de Matemática.

Optou-se por efetuar duas entrevistas, uma no início e outra no fim do ano letivo (2017/18), aos professores participantes, com o propósito de conhecer as práticas iniciais e as eventuais reformulações em função do conhecimento concreto dos alunos. A primeira entrevista (com duração entre quarenta minutos e uma hora) foi estruturada em nove blocos, distribuídos da seguinte forma: (i) Apresentação do estudo; (ii) Conceito de avaliação; (iii) Elementos que constituem o processo de avaliação; (iv) Instrumentos de avaliação utilizados; (v) Função da avaliação nas aprendizagens dos alunos; (vi) Efeitos da avaliação nas aprendizagens dos alunos com currículo específico individual; (vii) Inclusão dos alunos com currículo específico individual na escola e na turma; (viii) Participação da instituição escola/departamento de educação especial; (ix) Agradecimentos e conclusão da entrevista. A segunda entrevista (com duração de sete a quinze minutos) com o objetivo de concluir a recolha de dados foi estruturada em três blocos divididos da seguinte forma: (i) Relembrar os objetivos do estudo; (ii) Mudanças do processo de avaliação; (iii) Agradecimentos e conclusão da entrevista. Esta segunda entrevista não foi realizada aos professores de Educação Física e de Educação Musical. 
Neste estudo, o tratamento de toda a informação foi realizado através da análise de conteúdo (Bardin, 2009), sendo que todos os dados recolhidos foram organizados tendo por objetivo caracterizar os alunos e responder à questão de pesquisa.

\section{Resultados}

Os resultados da análise dos dados recolhidos foram organizados, neste artigo, tendo em apreciação os objetivos deste estudo.

\subsection{Práticas de avaliação dos alunos com currículo específico individual}

O processo de avaliação implica um clima democrático, participativo, humanizado e estimulante, em que o encorajamento do professor desempenha um papel muito importante no sucesso de cada aluno, "tu consegues" [Luís, Educação Física], e no feedback, "vamos andando pela sala e vamos dizendo, olha faz assim, não faças assim" [Alice, Português], numa perspetiva de uma avaliação para a aprendizagem. Na perspetiva destes professores, a avaliação dos alunos com currículo específico individual decorre da assiduidade, "para estes alunos já é difícil estar numa sala de aula, quanto mais estar atento" [Nuno, Educação Musical], do relacionamento interpessoal, "saber estar, o participar, a relação com os colegas" [Isabel, Inglês], da curiosidade e gosto pelo trabalho [Carolina, História e Geografia de Portugal], dos trabalhos realizados, traduzido num "faz ou não faz" [Ana, Matemática e Ciências Naturais], da capacidade de inserção na comunidade, "ensinar o essencial para uma vida futura" [Alice, Português], bem como das aquisições académicas funcionais.

As tarefas utilizadas para cada aluno são diferentes entre si e diferentes em relação à turma, "o trabalho é muito diferente" [Alice, Português], denotando-se uma preocupação geral na preparação para uma vida futura "vai-lhes ser exigido determinadas coisas que deveriam aprender na escola, autonomia, escrever, lutar para ultrapassar as dificuldades" [Ana, Matemática e Ciências Naturais], mas nem sempre se faz esse trabalho "existem conteúdos que eles não conseguiram concretizar" [Isabel, Inglês], apontando as causas para o comportamento da turma "nós não temos turmas tranquilas" [Isabel, Inglês] e para a falta de tempo do professor na sala de aula, "porque o professor não está só para eles" [Isabel, Inglês]. 


\subsection{Influência do desempenho na reformulação do currículo específico individual}

Os professores entrevistados demostram reconhecimento das necessidades de adaptações de tarefas e materiais, bem como na avaliação efetuada aos alunos com currículo específico individual, e todos realizam estas ações com o propósito de facilitar e promover o sucesso dos alunos. Este sucesso é influenciado pelos novos desafios, apresentados pelos professores, onde se executam tarefas, se resolvem problemas, mesmo os mais simples e se amplia a capacidade de autonomia e interação com os outros. Todos juntos vão fazer a diferença e sem se aperceberem estes professores estão a influenciar o currículo destes alunos ao tomarem atitudes de preocupação e não de indiferença, "Isto incomoda-me" [Ana, Matemática e Ciências Naturais], havemos de "arranjar um outro caminho" [Alice, Português].

No entanto, a perceção da maioria dos professores é que a avaliação não influência o currículo específico individual, sendo que este currículo é uma medida muito limitativa quanto ao futuro dos alunos. Só após uma avaliação rigorosa, ponderada e articulada, envolvendo professores, técnicos e família se deverá aplicar o currículo específico individual, sendo a sua alteração passiva de ser efetuada sempre que houver alterações significativas, no fim de um ciclo de estudo ou quando o próprio currículo específico individual prover.

\subsection{Educação inclusiva na turma e na escola}

A inclusão é vista como a forma de solucionar os problemas de integração dos alunos, sendo que o desejado seria que os alunos passassem o maior tempo possível junto da turma, "a verdadeira inclusão, para mim é tentar que estes alunos acompanhem os restantes" [Alice, Português]. Os professores apontam dificuldades de integração dos alunos no contexto da sala de aula, sem um apoio especializado, "estes alunos devem estar dentro da sala de aula, mas devidamente acompanhados" [Ana, Matemática e Ciências Naturais], por sentirem que não têm condições para os apoiar, "não consigo estar tão disponível para eles como seria desejável" [Isabel, Inglês].

A permanência destes alunos na sala de aula gera alguma incomodidade a alguns professores das disciplinas tidas por teóricas, "[existem] aulas minhas, em que eles se aborrecem bastante" [Isabel, Inglês], e aos restantes alunos, "eles [João e Pedro] estão bem integrados, mas (...) eles [restante turma] não os apoiam" [Carolina, História e Geografia de Portugal]. O professor Luís [Educação Física] considera que os alunos estão bem incluídos na turma e têm todo o apoio necessário. O professor Nuno [Educação Musical] acrescenta ainda, que a permanência dos alunos em sala de aula deve ser vista, caso a caso, sendo que as vantagens da inclusão são maiores nas disciplinas práticas. 


\section{Reflexão Final}

A diversidade de atividades e estratégias são uma constante nas práticas de avaliação dos professores, não esquecendo a afetividade que consideram incluída no processo. Contudo, o trabalho colaborativo, a partilha de experiência, bem como as discussões inerentes às práticas letivas, não são uma constante entre estes professores, embora alguns façam referência à importância da colaboração do professor de educação especial, considerado indispensável na concretização do currículo específico individual, quer no apoio direto e concreto quer na elaboração de materiais. As práticas de avaliação dos alunos com currículo específico individual podem ser condicionadas por essa dualidade de considerações assumidas pelos professores, contrariando as potencialidades do trabalho colaborativo entre profissionais.

Os professores apontam a falta de acompanhamento dentro da sala de aula, por falta de tempo do professor da disciplina e por ausência do professor especializado em educação especial, como um dos motivos do insucesso dos alunos. Todos falam de inclusão e todos sentem necessidade de aprender e articular tarefas e estratégias especializadas e se tornarem eles próprios professores especializados, no entanto não procuram formação nem a colaboração dos professores especializados. Acreditamos que uma avaliação adequada e correta é um fator importante de inclusão e constitui uma resposta adequada e necessária ao desenvolvimento de todos os alunos.

\section{Referências}

Abrantes, P. (2001) Reorganização Curricular do Ensino Básico: Princípios, Medidas e Implicações. Departamento da Educação Básica. Lisboa: Ministério da Educação.

Bardin, L. (2009). Análise de Conteúdo. Lisboa: Edições 70.

Bogdan, R., \& Biklen, S. (1994). Investigação Qualitativa em Educação: Uma Introdução à Teoria e aos Métodos. Porto: Porto Editora.

Booth, T., \& Ainscow, M. (2002). Índex para a inclusão, desenvolvendo a aprendizagem e a participação na escola. Bristol: CSIE.

Colôa Dias, J. (2014). Avaliação para as Aprendizagens de Alunos com Necessidades Educativas Especiais no $1 .^{\circ}$ Ciclo do Ensino Básico: da Diversidade da Avaliação à Avaliação da Diversidade. [Tese de Doutoramento em Educação]. Universidade de Lisboa, Portugal. 
Peralta, M. H. (2002). Como avaliar competência(s)? Algumas considerações. In Abrantes, P. \& Araújo, F. (coord.) Avaliação das Aprendizagens - Das concepções às práticas (24-34) Departamento da Educação Básica. Lisboa: Ministério da Educação.

Reis, C. S., \& Neves, F. S. (2011). Livro de Atas do XI Congresso da Sociedade Portuguesa de Ciências da Educação. Guarda: Instituto Politécnico da Guarda.

Roque, M. T. (2018). Avaliação de alunos com currículo específico individual: práticas pedagógicas no 2. ${ }^{\circ}$ ciclo do ensino básico. [Tese de Mestrado em Educação Especial: Domínios Cognitivo e Motor]. Universidade do Algarve, Portugal.

UNESCO (2005). Orientações para a Inclusão: Garantindo o Acesso à Educação para Todos. França: UNESCO. 